The present population of 0.3 million has already exceeded the carrying capacity of the islands. The scarcity of drinking water, electricity, food commodities, transport, and subsidies in various sectors, are the major constraints of permitting mass tourism. However, Nature and adventure-upmarketing ecofriendly package tourism can be developed, though only after careful consideration of deforestation, soil and coastal erosion, disposal of nonde- gradable wastes, and due sanitation to conserve and preserve indispensable biodiversity for future generations.

T.C. KHATRI
GC-3, Government College Colony
Port Blair 744104
Andaman Islands
India.

\title{
International Energy Foundation
}

$\mathrm{T}$ he International Energy Foundation (IEF) was formally established in 1989 as a non-profit organization having the main objective of fostering world education and scientific research on all aspects of energy production, management, distribution, conservation, and use -- with one of the emphases being on renewable sources of energy and the environment. The Foundation is the outcome of a series of recommendations from representatives of more than 70 countries who participated in the international energy 'Energex' forums in 1982, 1984, and 1988. IEF's main mission is to facilitate the trans ler of the benefits of research and technology in all areas of energy, with special emphasis on renewable sources among emerging nations.

IEF has an international Board of Directors from 10 countries, who bring.a global perspective to our operation. We have also established regional headquarters for Eastern Europe (Moscow), the Middle Filst (Bahrain), Northern Africa (Egypt), North America (Regina), and Australia (Canberra). Others will be announced as they are established in due course.
We are currently in the final stage of development for Energex '96 (Beijing) and the early stages for Energex '98 (Bahrain) and Energex AD 2000 (Palm Springs). More recently the 1993 Seoul Resolutions (an outcome of Energex ' 93 ), approved by the Board of Directors, resulted in the planned establishment of the Foundation's world headquarters in Geneva, Switzerland, to serve IEF's 8.000 contacts in more than 75 countries'.

If you would like to participate in sharing knowledge in this vital field with the rest of the world, please write to the undersigned:

PETER J. CATANIA (Prof. Dr), Chairman
International Energy Foundation
I777 Victoria Avenue
Regina
Saskatchewan S4P $3 C 4$
Canada

Fax: (1 306) 7818364.

\section{The London Environment Centre}

\section{Background}

'The environment' as a topic hals permeated almost all areas of working life and has developed far beyond the traditional Nature conservation aspects such as species survival and habitat maintenance. However, Nature conservation measures taken at local level may have limited effects, set against the environmental changes brought about by larger-scale phenomena such as acid rain, global warming, and stratospheric ozonc depletion. The realization of the link between macro-kevel activities in cities, factories, and the built environment in general, and their profound effect on the species and habitats we seek to preserve at local level, is resulting in programmes of action as the 'act locally, think globally' maxim gathers momentum.

Consequently, there is an urgent need to raise the level of environmental awareness of decision-makers, business, and industry, as well as of governments, to encourage positive environmental action. However, efforts directed towards this end have not always met with success. Perhaps only increasing legislation and the possibilities of severe penalties will make organizations in both public and private sectors begin to take serious account of the environmental impact of their actions.

\section{Numerous EU Environmental Dirctives}

There are now over 300 Europcan Union (EU) Directives concerning the environment in addition to National and local legislation in individual countries. In the manner of every country in the EU, the UK has passed legislation both to implement pertinent EU Directives and to support its own environmental policies. The government has stated that its commitment to sustainable development will result in more restrictive environmental legislation being enacted in future. This, and the financial and other consequences of failing to comply with environmental legislation, have finally resulted in a higher profile for environmental matters in a wide range of organizations. However, the Small and Medium Enterprise (SME) sector remains largely unaffected by environmental considerations. This may be as a consequence of the impact of the recession and of ongoing financial problems in this sector.

Another factor in the heightened profile of environmental matters is increasing public environmental awareness, which has caused the environment to enter the agenda of most of the major political parties in Europe. The general public now have an expectation of positive measures from governments to improve living conditions through measures aimed at protecting and improving the environment. Consumer power is also acting to influence the environmental standards of goods, services, and manufacuring processes, although mechanisms for disseminating accurate environmental information to the public are not fully effective.

\section{Environment an Integral Part of Business}

The fundamental change in thinking that has occurred over the past few years has been to view the environment as an integral consideration to all business operations and activities. Indeed, the essence of sustainable development as promoted at the Rio Summit was not to put the brakes on economic growth and development (which was previously the main tone of the 'environmental' message); rather that 